\title{
Endogenous Modulation of ACh Release by Somatostatin and the Differential Roles of $\mathrm{Ca}^{2+}$ Channels
}

\author{
D. B. Gray, D. Zelazny, N. Manthay, and G. Pilar \\ Department of Physiology and Neurobiology, The University of Connecticut, Storrs, Connecticut 06269
}

The classical neurotransmitter acetylcholine (ACh) and the potential modulatory peptide somatostatin are colocalized in terminals of avian choroid neurons. We previously showed that exogenous somatostatin inhibits $\mathrm{ACh}$ release in the choroid coat (Gray et al., 1989b). In the present work we determine whether endogenous somatostatin plays a role in neuromodulation and what mechanisms are involved. To determine its role and its mode of secretion, voltage-sensitive $\mathrm{Ca}^{2+}$ channels in these terminals were identified pharmacologically using $\mathrm{Ca}^{2+}$-dependent $\mathrm{K}^{+}$-evoked $\mathrm{ACh}$ release. Release of the primary transmitter $\mathrm{ACh}$ was triggered in the presence of high $\mathrm{K}^{+}$by $\mathrm{Ca}^{2+}$ influx primarily via dihydropyridine (DHP)-insensitive channels, while inhibition of ACh release occurred when L-type channels were activated by the DHP agonist Bay $K$ 8644. The somatostatin antagonist cyclo(7-aminoheptanoyl-phe-D-trp-lys-thr (BZL)) (CyCam) blocks the inhibition of $\mathrm{ACh}$ release induced by the agonist Bay K 8644 and indicates that endogenous somatostatin may normally modulate ACh release. Additionally, nifedipine, a DHP antagonist, and pertussis toxin, known to antagonize somatostatin's effect on ACh release, both reverse the Bay $K \mathbf{8 6 4 4}$ effect on ACh release. Although the release of labeled $\mathrm{ACh}$ in the first $3 \mathrm{~min}$ collection period was not significantly affected by CyCam or nifedipine alone, release in the first minute was enhanced by $50 \%$ in the presence of $10 \mu \mathrm{M}$ nifedipine. Preincubation with CyCam alone also increased ACh release. These results support the hypothesis that endogenous somatostatin is physiologically released during the initial minute of depolarization in high $\mathrm{K}^{+}$and that this release is mediated by DHP-sensitive $\mathrm{Ca}^{2+}$ channels.

Previously we reported that exogenous somatostatin inhibits $\mathrm{K}$ '-evoked ${ }^{3} \mathrm{H}$-ACh release in terminals in the vascular smooth muscle of the chick choroid and that this inhibition is blocked by pertussis toxin (PTX), indicating mediation by a $G$ protein. Experiments with a $\mathrm{Ca}^{2+}$ ionophore indicated that modulation occurred at the level of $\mathrm{Ca}^{2+}$ entry (Gray et al., 1989b). Since

\footnotetext{
Received Nov. 24, 1989; revised Mar. 19, 1990; accepted Mar. 20, 1990.

We thank Ms. Maura Ford for somatostatin staining and some of the photography of the intact ganglion and choroid, Dr. L. Khairallah for her EM work, and Mr. L. Cupceancu for his technical support. We thank Drs. L. Landmesser, J. Covault, and C. Bowers for their criticisms and suggestions, and Ms. Sara Putnam for her help in editing and preparing this manuscript. We also thank Dr. A. Scriabine and Miles Laboratories (West Haven, CT) for their gift of Bay K 8644 . Support provided by the University of Connecticut Research Foundation and NIH Grants 10338 and NS07324 and NSF Grant BNS-8410581.

Correspondence should be addressed to Guillermo Pilar, The University of Connecticut., Department of Physiology and Neurobiology, 75 N. Fagleville Rd., Storrs, CT 06269.

Copyright (c) 1990 Society for Neuroscience $0270-6474 / 90 / 082687-12 \$ 03.00 / 0$
}

somatostatin is colocalized with $\mathrm{ACh}$ in the terminals of the choroid neurons of the ciliary ganglion (Epstein et al., 1988; Gray et al., 1989b), we decided to investigate if endogenous somatostatin is released and what mechanisms are involved in the modulation of $\mathrm{ACh}$ secretion.

Specifically, we were interested in determining if somatostatin is released during high-K $\mathrm{K}^{+}$incubation, if this release is $\mathrm{Ca}^{2+}$ dependent, and if the flux responsible for peptide release is through voltage-dependent channels distinct from those that trigger ACh release. We showed that this $\mathrm{K}^{+}$-stimulated release of ${ }^{3} \mathrm{H}$-ACh is not antagonized by nifedipine (Gray et al., 1989b), indicating that $\mathrm{Ca}^{2+}$ flux through L-type $\mathrm{Ca}^{2+}$ channels probably does not trigger this $\mathrm{Ca}^{2+}$-dependent event.

It is generally accepted that in nerve terminals, $\mathrm{Ca}^{2+}$ influx couples depolarization to transmitter release. Two kinds of voltage-dependent $\mathrm{Ca}^{2+}$ channels have been implicated in transmitter release (Carbone and Lux, 1983; Perney et al., 1986; Miller, 1987; Yeager et al., 1987; Miller, 1988): L-type [characterized by Nowycky et al. (1985) as high-threshold, high-conductance, slowly inactivating or noninactivating] and N-type (high-threshold, DHP insensitive). The presence of at least 2 separate types of voltage-sensitive $\mathrm{Ca}^{2+}$ channels in the same nerve terminal preparation has been shown using kinetics (Lemos and Nowycky, 1989) and pharmacology (Atchison and O'Leary, 1987). It has been proposed that L-type $\mathrm{Ca}^{2+}$ channels preferentially trigger peptide release, while N-type channels preferentially trigger release of ACh or catecholamines (Miller, 1987; Hirning et al., 1988; Lipscombe et al., 1989). However, this distinction has never been made in intact nerve terminals, where peptides and classical transmitters are colocalized. Although it is important to study the localization and molecular behavior of these $\mathrm{Ca}^{2+}$ channels, it is also important to determine the role that each channel type may play in synaptic transmission because they are likely targets for modulatory mechanisms.

Numerous studies (i.e., in cell bodies of cultured neurons, in which direct recording is possible) have characterized different types of $\mathrm{Ca}^{2+}$ channels both electrophysiologically and pharmacologically (for review, see Miller, 1987). However, because the small size of intact choroid terminals precludes direct measurement of $\mathrm{Ca}^{2+}$ currents, we have distinguished the types of channels involved in secretion in the choroid primarily by pharmacological means, using $\mathrm{Ca}^{2+}$-dependent $\mathrm{ACh}$ release as an indicator of $\mathrm{Ca}^{2+}$ entry.

The anatomical colocalization of 2 or more neuroactive substances in the same neurons or terminals has been amply demonstrated in many peripheral and central neuronal synapses (Hökfelt et al., 1987), but studies of functional mechanisms of 
co-release are more scarce (Bartfai et al., 1988), probably because few preparations are amenable for such studies (Lundberg et al., 1981; Allen et al., 1982; Jan and Jan, 1982; Campbell and Jackson, 1985). The chick choroid coat, densely innervated by neuronal processes of the ciliary ganglion, is one such preparation.

In this report, we provide evidence that endogenous somatostatin is released by $\mathrm{K}^{+}$depolarization. Furthermore, pharmacological evidence is advanced for the existence of 2 types of voltage-dependent $\mathrm{Ca}^{21}$ channels (DHP sensitive and DHP insensitive) in the cholinergic terminals of the chick choroid. We suggest that these $\mathrm{Ca}^{2+}$ channels independently mediate release of the primary neurotransmitter in our system, ACh (via DHPinsensitive channels), and of the endogenous peptide somatostatin (via DHP-sensitive channels), which in turn inhibits $\mathrm{ACh}$ release, acting via a voltage-dependent $\mathrm{Ca}^{2+}$ channel. Preliminary reports of these observations have been previously published in abstract form (Gray and Pilar, 1988; Gray et al., 1989a).

\section{Materials and Methods}

\section{Choroid and iris preparations}

Whole irises and stereotypic wedges consisting of approximately onethird of the innervated choroid were isolated as described previously (Vaca and Pilar, 1979; Gray et al., 1989b). These tissues contain synapses between ciliary ganglion neurons and either choroid smooth muscle (Meriney et al., 1987) or striated iris muscle (Vaca and Pilar, 1979), both of which possess high-affinity Na'-dependent choline uptake-mediated ACh synthesis (Vaca and Pilar, 1979; Gray et al., 1989b). The iris preparation - which is similar to the choroid in that it is an innervation target of parasympathetic cholinergic neurons, but dissimilar in that it does not contain somatostatin-positive cells or processes-serves as a useful control for many of our pharmacological manipulations.

\section{Assay of labeled $A C h$ release}

Choroid and iris preparations were preincubated in oxygenated Tyrodes (134 mM NaCl, $3 \mathrm{~mm} \mathrm{KCl}, 20.5 \mathrm{~mm} \mathrm{Na} \mathrm{HCO}_{3}, 3 \mathrm{~mm} \mathrm{CaCl}, 1 \mathrm{~mm}$ $\mathrm{MgCl}_{2}$, glucose, $2.2 \mathrm{gm} /$ liter) containing ${ }^{3} \mathrm{H}$-Ch (final specific activity, $8.1 \mathrm{Ci} / \mathrm{mole}$; total choline concentration at $1 \mu \mathrm{M}$ ) and $0.5 \% \mathrm{BSA}$ for 70 min at $37^{\circ} \mathrm{C}$ and washed by centrifugation as described previously (Gray et al., 1989b). Prestimulation release of ${ }^{3} \mathrm{H}$-ACh was measured in $5 \mathrm{~min}$ collection periods during preincubation in normal Tyrodes at $37^{\circ} \mathrm{C}$. To evoke release from terminals in the iris and the choroid, the tissues were incubated in $55 \mathrm{~mm} \mathrm{KCl}$ Tyrodes (equimolar substitution for $\mathrm{NaCl}$ ) for time periods as indicated in the text or figure captions. Release values were converted to disintegrations/min (DPM) and expressed per minute of collection time. The collection times varied from 1 to $10 \mathrm{~min}$, and the values are expressed as averages of DPM/min or as percentages of the last prestimulation period counts for that sample.

Figure 1 shows a dose-response relationship between $\mathrm{K}^{+}$concentration and evoked ACh release for the initial 3 min period. Although 28 $\mathrm{mM} \mathrm{KCl}$ does not evoke an increase in $\mathrm{ACh}$ release, $110 \mathrm{mM} \mathrm{KCl}$ stimulates further release of labeled ACh over that at $55 \mathrm{~mm} \mathrm{KCl}$. In most of the experiments described here, $55 \mathrm{mM} \mathrm{K}^{+}$was used to evoke release. All release solutions, normal, zero- $\mathrm{Ca}^{2+}$ or high- $\mathrm{K}^{+}$Tyrodes, contained BSA to prevent adhesion of tissues to sides of tubes or bubbler needles and $10 \mu \mathrm{M}$ eserine sulfate to inhibit any endogenous cholinesterases present. DHP stocks were stored in opaque containers to prevent loss of activity due to exposure to light. Experiments in which these drugs were used were conducted under red light. DHP incubations during evoked release were always preceded by a $5 \mathrm{~min}$ preincubation in the normal Tyrodes bath, to ensure adequate time for binding and diffusion into tissues. In cases where DHP compounds had no effects, we increased preincubation time up to $15 \mathrm{~min}$ without affecting results. However, we avoided prolonged incubation of cells with DHPs and the carrier DMSO because there is evidence that nifedipine and related antagonists may diffuse intracellularly and modify cytoplasmic $\mathrm{Ca}^{2+}$ (Pang and Sperelakis, 1983a, b). This was apparent in our preparation since incubation of choroids with $10 \mu \mathrm{M}$ nifedipine for $15 \mathrm{~min}$ or longer during tissue loading of ${ }^{3} \mathrm{H}-\mathrm{Ch}$ prevents accumulation of labeled $\mathrm{ACh}$ (unpublished observations). ${ }^{3} \mathrm{H}-\mathrm{ACh}$ was separated from ${ }^{3} \mathrm{H}-\mathrm{Ch}$ by high- voltage paper electrophoresis and measured by scintillation counting as described previously (Vaca and Pilar, 1979; Gray et al., 1989b). Statistical analyses of data were performed using a 2-tailed Student's $t$ test.

\section{Immunological staining of choroid tissues}

Synaptic vesicle-specific antibody. A triangular wedge of tissue similar to that used for the ACh release experiments was dissected free in oxygenated zero- $\mathrm{Ca}^{2+}$ Tyrodes. After removing the retina, any remaining pigment epithelium was removed from the tissue with a cotton bud and the choroid coat was dissected free from the sclera and pinned flat in a Sylgard-coated dish. The tissue was fixed for $30 \mathrm{~min}$ in ice-cold $4 \%$ paraformaldehyde and washed 3 times for $10 \mathrm{~min}$ each time in phosphate buffer with $0.3 \%$ Triton X-100 (PBT) before incubation in the monoclonal antibody SV2 (provided by K. Buckley, Harvard University), diluted 1:10 in BSA/phosphate buffer (PB), overnight at $4^{\circ} \mathrm{C}$. This antibody binds to an undefined synaptic vesicle protein present in apparently all secretory vesicles (Buckley and Kelly, 1985). The choroids were washed 3 times in PBT for 30 min each time and were incubated with goat-anti-mouse IgG conjugated to fluorescein isothiocyanate (FITC) (Sigma) at $1: 50$ in $2 \%$ BSA in PBT for $30 \mathrm{~min}$ at room temperature, then washed again 3 times in PB for 30 min each time and mounted flat between 2 coverslips in Fluoromount G.

Photographs were taken using a confocal fluorescence microscope (courtesy of the BioRad Corporation, Richmond, CA). A composite image was constructed from a high-resolution video screen containing 12 contiguous focal planes of $0.5 \mu \mathrm{m}$ each.

Antibodies against peptides. The choroid, dissected as above, was immediately fixed, stained for somatostatin, and mounted as described previously (Gray et al., 1989b). Choroids were incubated in rabbit antisomatostatin antiserum (Axell, distributed by Accurate Scientific, Westbury, NY) at a $1: 400$ dilution for $24-48 \mathrm{hr}$ at $4^{\circ} \mathrm{C}$. This polyclonal antibody was raised against synthetic cyclic somatostatin 1-14, but it cross-reacts with synthetic cyclic somatostatin 14-28. The secondary antibody was goat anti-rabbit IgG conjugated to FITC. Antibody specificity was tested by replacing the primary antiserum with preadsorbed antiserum at the same dilution containing $50 \mu \mathrm{g} / \mathrm{ml}$ synthetic cyclic somatostatin $14-28$ or with nonimmune rabbit serum. Similar techniques were used with irises.

\section{Differential distribution of somatostatin-positive neurons in the ciliary ganglion}

Embryonic stage 43 chick ciliary ganglia were dissected free in zero$\mathrm{Ca}^{2+}$ Tyrodes and fixed for $3 \mathrm{hr}$ in $4 \%$ paraformaldehyde in $0.1 \mathrm{M} \mathrm{PB}$. Ganglia were then washed 3 times in $20 \%$ sucrose in PB over $24 \mathrm{hr}$ at $4^{\circ} \mathrm{C}$. Each ganglion was then embedded in OCT compound (Tissue Tek) and frozen in 2-methyl butane on dry ice. Serial $10 \mu \mathrm{m}$ frozen sections were cut through an entire ganglion, collected on subbed slides, dried overnight, and washed 3 times in PBT. Sections were then preincubated for $1 \mathrm{hr}$ at room temperature in a blocking solution containing $2 \%$ BSA in PBT. The sections were then incubated for $24 \mathrm{hr}$ at $4^{\circ} \mathrm{C}$ in a rabbit antiserum against somatostatin (a gift from Dr. Garcia-Arraras, University of Puerto Rico), diluted 1:500 in blocking solution. The sections were washed in PBT and subsequently incubated in goat anti-rabbit FITC (Sigma), diluted 1:50 in blocking solution, for $1 \mathrm{hr}$ at room temperature. A final rinse in PB was done before the sections were mounted in Fluoromount $\mathrm{G}$ and viewed under epifluorescence with FITC filters on a Nikon Labophot microscope. Similar controls for specificity of antibody binding were conducted as described in the preceding section.

Ganglionic sections were oriented by the presence of a blood vessel which runs longitudinally along the ventrolateral border of the ganglion. The choroid region was recognized by the presence of small cells and its ventral position in the ganglion (Pilar et al., 1980). All sections were photographed on $35 \mathrm{~mm}$ film, and reconstruction of the ganglion was done by projecting the negatives on a TV screen and tracing the somatostatin-positive neurons and the outline of the ganglion on acetate sheets.

\section{Electron microscopy}

Choroids isolated from 1- to 4-d-old chicks were fixed in a solution of $1.5 \%$ glutaraldehyde, $1.5 \%$ paraformaldehyde, and $1.5 \%$ acrolein in 0.1 $\mathrm{M}$ cacodylate ( $\mathrm{pH} 7.3$ ) for $5 \mathrm{hr}$. They were then postfixed in $2 \%$ osmium tetroxide for $1 \mathrm{hr}$ and dehydrated for embedding in Epon Araldite. Thin sections stained with $2 \%$ uranyl acetate and $1.5 \%$ lead citrate were 


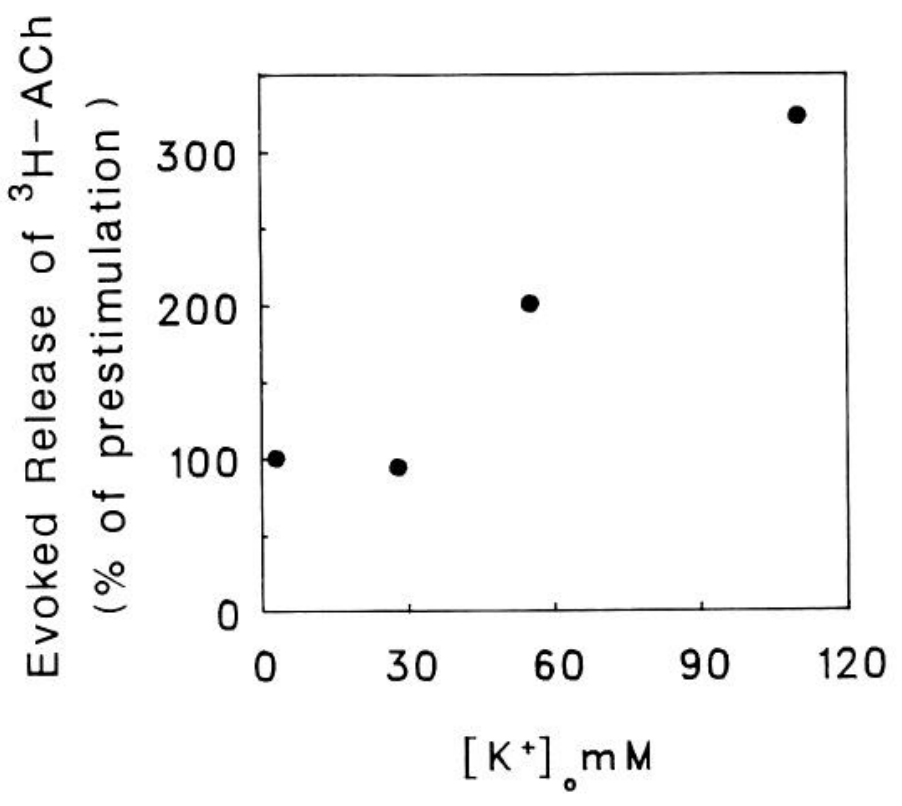

Figure 1. Evoked ${ }^{3} \mathrm{H}-\mathrm{ACh}$ release from the chick choroid as a function of extracellular $\mathrm{K}^{+}$concentration. Osmolarity was maintained by replacing $\mathrm{NaCl}$ with $\mathrm{KCl}$. Choroid wedges containing intact terminals from the ciliary ganglion neurons of 1- to 4-d-old chicks were excised and incubated in oxygenated Tyrodes containing ${ }^{3} \mathrm{H}-\mathrm{Ch}$, washed, and analyzed for ${ }^{3} \mathrm{H}-\mathrm{ACh}$ release as described (see Materials and Methods). Release of ${ }^{3} \mathrm{H}$-ACh during a 3-min incubation in Tyrodes containing the $\mathrm{K}^{+}$concentrations shown above is expressed as a percentage of $\mathrm{DPM} / \mathrm{min}$ counts of the immediate prestimulation period. Values are the average of 2 separate experiments. viewed and photographed with a Phillips 300 TEM. Flat and longitudinal sections were studied.

\section{Materials}

${ }^{3} \mathrm{H}$-acetylcholine $\left({ }^{3} \mathrm{H}-\mathrm{ACh}\right)$ and ${ }^{3} \mathrm{H}$-choline $\left({ }^{3} \mathrm{H}\right.$-Ch) were obtained from New England Nuclear (Boston, MA). The following drugs and reagents were purchased from Sigma Chemical Co. (St. Louis, MO): A 23187, bovine serum albumin (BSA), D-600, eserine sulfate, dimethyl sulfoxide (DMSO), nifedipine, somatostatin 14-28, pertussis toxin (PTX), $\omega$-conotoxin, cadmium chloride, verapamil, and cyclo(7-aminoheptanoylphe-D-trp-lys-thr (BZL)) (CyCam). The following lipid-soluble substances were dissolved in $100 \%$ DMSO stock solutions and the final DMSO concentrations of the incubation solution was $0.1 \%$ : nifedipine, A 23187 , D-600, PTX, and Bay K 8644. These compounds were kept in opaque containers.

\section{Results}

Localization of somatostatin-immunoreactive cells in the ciliary ganglion and its synaptic targets

Previously we have shown the localization of somatostatin in the cholinergic processes of the ciliary ganglion in the choroid preparation using cytoskeleton and somatostatin antibodies. This colocalization of $\mathrm{ACh}$ and somatostatin in the choroid terminals is in contrast to the clear lack of somatostatin immunoreactivity in the iris (Gray et al., 1989b; see also Epstein et al., 1988). We pursued the subject further by localizing the somatostatin immunoreactivity in the parent cell bodies in the ciliary ganglion of the terminals of the synaptic targets. We also provide further evidence of the colocalization of somatostatin and $\mathrm{ACh}$ in the choroid varicosities.

In the single section shown in Figure $2 A$, the choroid region
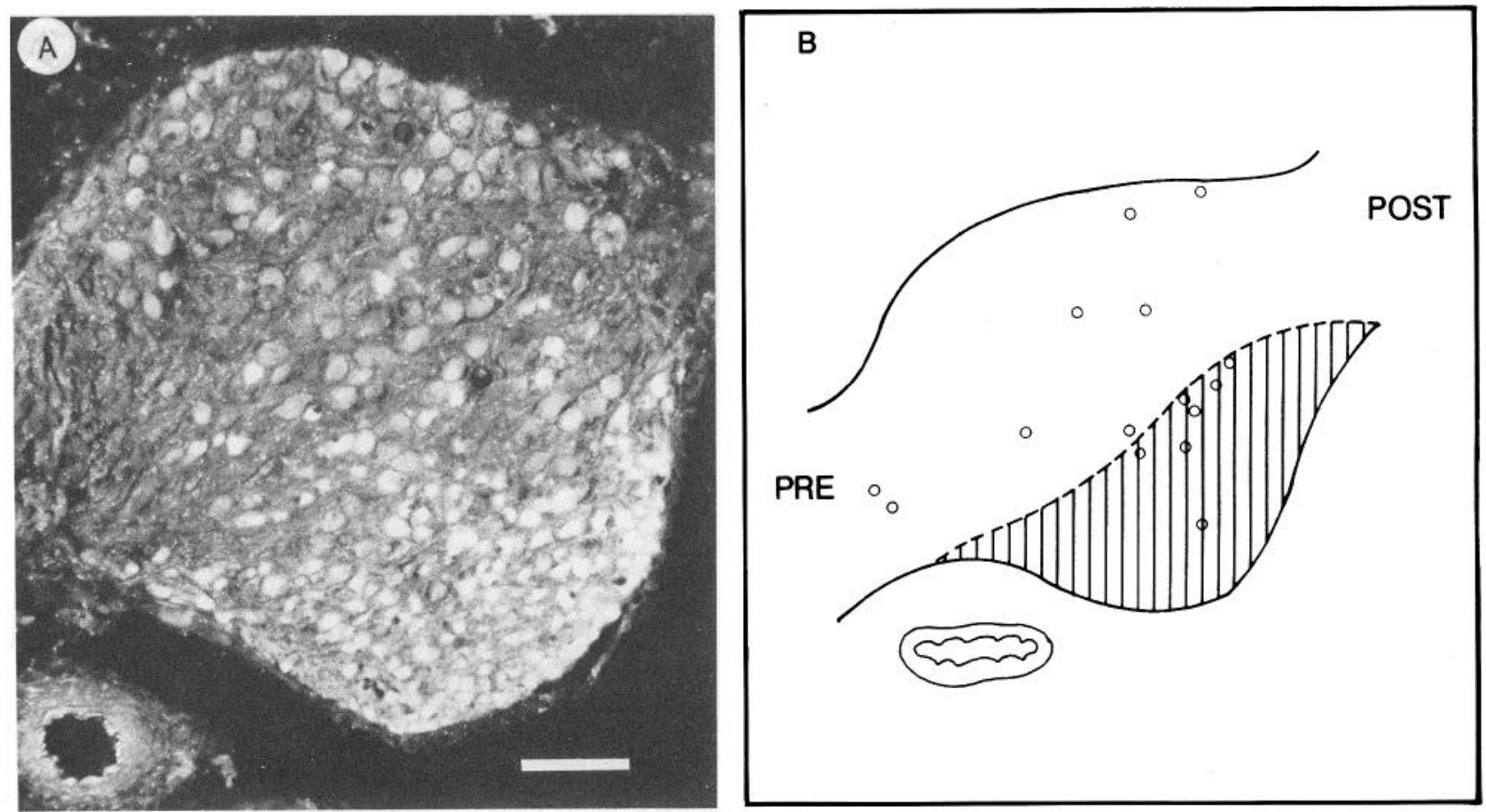

Figure 2. A, Representative histological section of a stage 43 ciliary ganglion, showing the preferential localization of choroid cells identified with somatostatin antibody (bottom right) and the larger ciliary cells (top). Sections like this one were used to serially reconstruct the ganglion in 2 dimensions. Fluorescence photography was done through a \#5 FITC filter. Scale bar, $50 \mu \mathrm{m}$. B, Partial reconstruction of a serially sectioned ganglion. Images of 4 serial sections spaced from the presynaptic $(P R E)$ to the postsynaptic $(P O S T)$ were superimposed. Sections were made oblique to the longitudinal axis of the ganglion. Dashed line indicates the border between ciliary and choroid region. In the striped choroidal region all cells were immunoreactive with somatostatin antibody. The round circles indicate large cells, also stained with the antibody, scattered throughout the ganglion. 

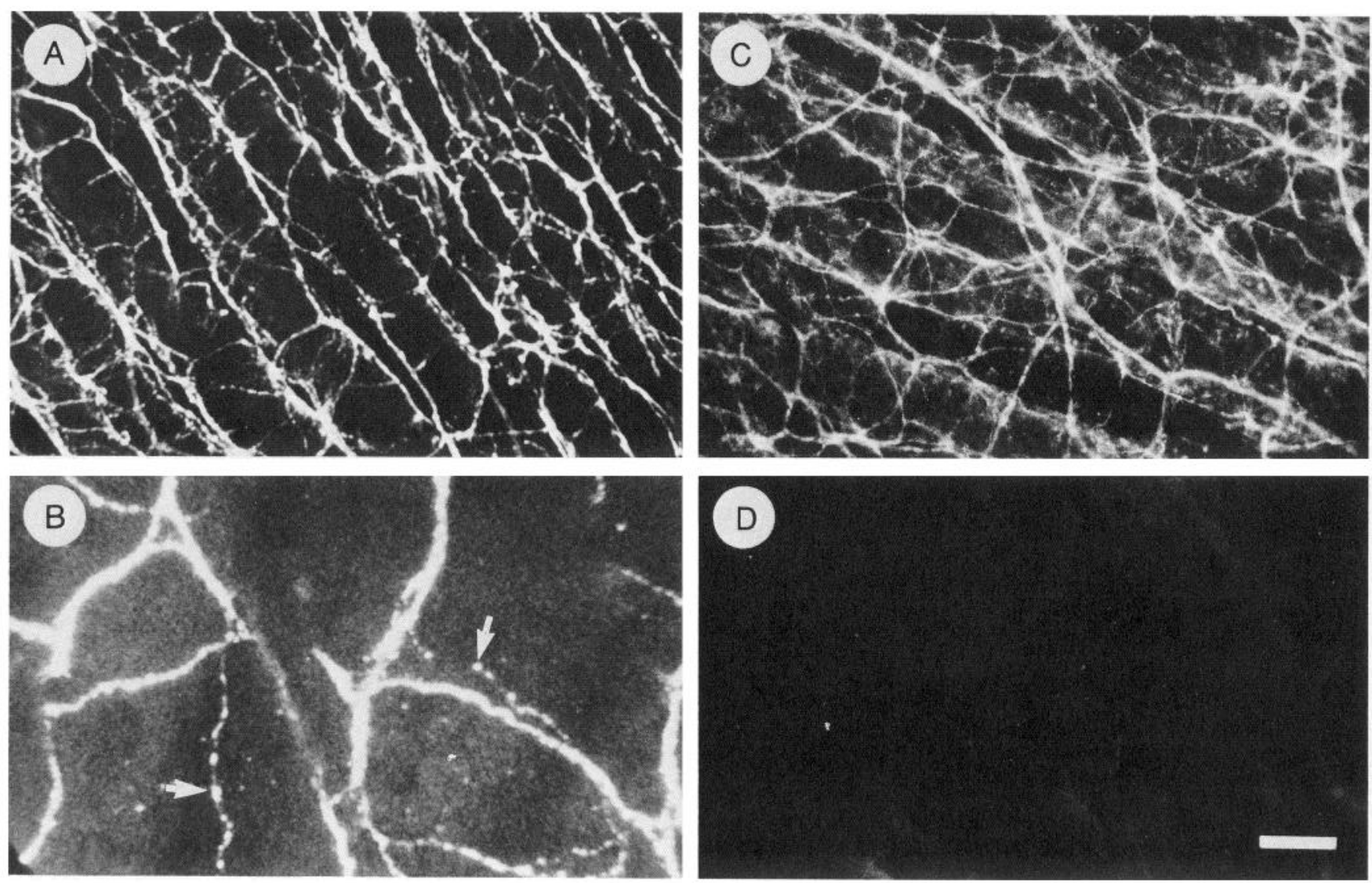

Figure 3. A, Whole mount of a hatchling choroid stained with antibodies to synaptic vesicle antigen (SV2), using secondary antibody conjugated to FITC. Photography was carried out through a confocal fluorescence microscope using a composite image from a high-resolution video screen containing images from 12 contiguous focal planes of $0.5 \mu \mathrm{m}$ each. Antibody-defined parallel tracts appear to send branches that coil around blood vessels. $B$, With the confocal reconstruction, it is possible to observe single axons with uneven distribution of synaptic vesicle antigen (varicosities, arrow). $C$, Whole mount of another choroidal coat reacted with somatostatin antibody (Axell, 1:400 dilution). Processes staining positive have a similar distribution to those in $A$. Longitudinal outlines of blood vessels can be distinguished. $D$, Controls: whole mount of choroidal coat reacted with anti-somatostatin which was preincubated for $36 \mathrm{hr}$ with $50 \mu \mathrm{g} / \mathrm{ml}$ cold somatostatin. Although there remains some autofluorescence, no structures can be recognized. Scale bar: $A, C$, and $D, 100 \mu \mathrm{m} ; B, 20 \mu \mathrm{m}$.

is in the lower portion, corresponding to the striped region in the serially reconstructed ganglion shown in Figure $2 B$. It is clear that virtually all of the choroid cells (distinguished by both position and smaller cell bodies) (Pilar et al., 1980) are somatostatin positive. In addition, larger neurons, also somatostatin positive, are scattered throughout the ganglion. The positions of these cells in several sections, near the presynaptic nerve, in the midsection, and near the postsynaptic nerve, are denoted by circles in Figure $2 B$. It is not clear if these and similar cells in other sections ( 62 cells in 20 sections, corresponding to $<10 \%$ of the total ciliary population) are misplaced choroid cells or a somatostatin-containing subpopulation of ciliary neurons. However, because this is such a small percentage and because our previous study of ganglionic nerve terminals shows that somatostatin is restricted to the choroid (Gray et al., 1989b; see also Epstein et al., 1988), we conclude that the choroid population rather than the ciliary contains most of the endogenous somatostatin.

Figure 3 shows that somatostatin is contained within the processes of the choroid neurons, which form a dense meshwork of nerve fibers wrapped around the abundant small blood vessels and contain synaptic varicosities. In Figure $3 A$, the nerve plexus is visualized with SV2, a synaptic vesicle antigen that stains most terminal fibers because of their abundant synaptic vesiclecontaining varicosities (see also Fig. 4). Figure $3 B$ shows synaptic vesicle antigen staining at higher magnification, while Figure $3 C$ shows a similar region stained with anti-somatostatin. It is clear that somatostatin reactivity is distributed fairly uniformly throughout the plexus of terminal nerve fibers. However, in both, especially in terminal regions, the varicose nature of the staining is apparent (Fig. $3 B$, arrows; see also Fig. 4). Similar whole mounts were stained with primary antisera to somatostatin which had been preadsorbed with excess exogenous somatostatin. These show no staining for somatostatin-positive nerve fibers, although some background autofluorescence remains (Fig. 3D).

Figure $3 A$ is remarkably similar to Figure $3 B$ in Gray et al. $(1989 \mathrm{~b})$, in which cytoskeleton antibody was used to reveal the choroid nerve network. One reason for the high density of the SV2 staining of Figure $3 A$ became clear when the tissue was studied with the electron microscope. Figure 4 is a low-power micrograph in which axon fascicles can be seen embedded in the choroid coat matrix. Of the large number of axon profiles observed, many have clear synaptic vesicles (v), and a smaller percentage of these profiles also contain large dense core vesicles (Dv). 


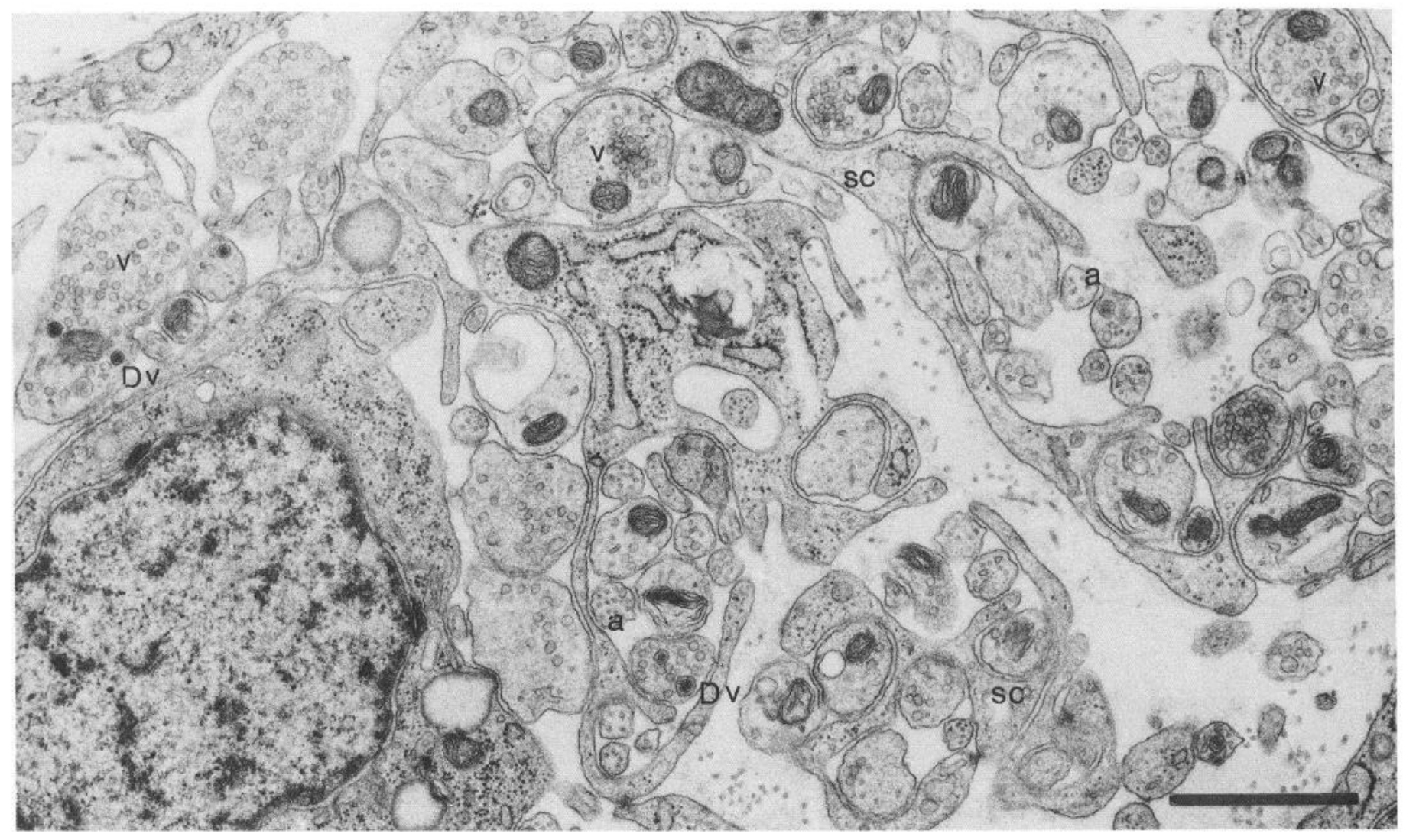

Figure 4. EM micrograph of a cross-section of bundles of unmyelinated axons $(a)$ and varicosities in the choroid of the 2-d-old chick. Some of the axons are partially encircled by Schwann cell processes $(s c)$. Most of the axons contain clear vesicles $(v)$, which in some cases are clustered. There are also profiles with dense-core vesicles $(D v)$ colocalized with clear vesicles in the same varicosity. In the lower-left corner, some of these varicosities are in close proximity to what is probably a smooth muscle cell. At this stage, it is difficult to recognize smooth muscle cells because the filaments are usually at the ends of the cells and the varicosities are in the bulging middle part of the cells, which contain the large nuclei. Scale bar, $1 \mu \mathrm{m}$.

\section{$\mathrm{Ca}^{2+}$ channels and ACh release}

Incubation of choroid wedges in 55 and $110 \mathrm{~mm} \mathrm{~K}^{+}$Tyrodes increased ${ }^{3} \mathrm{H}-\mathrm{ACh}$ release by 2 - and 3 -fold, respectively, the characteristics of which are summarized in Table 1. This evoked release of ${ }^{3} \mathrm{H}-\mathrm{ACh}$ from choroid terminals was inhibited by removal of external $\mathrm{Ca}^{2+}$ and blocked by cadmium $(\mathrm{Cd})$ or $\omega$-conotoxin $(\omega$-CgTX). This inhibition was irreversible even after 12 washes in toxin-free Tyrodes over $30 \mathrm{~min}$, suggesting that $\mathrm{Ca}^{2+}$ entry through T-type voltage-dependent channels is not responsible for triggering labeled $\mathrm{ACh}$ release (McClesky et al., 1987). DHP antagonists such as nifedipine, verapamil, and D600 had no effect on $\mathrm{K}^{+}$-evoked release even at concentrations of $10 \mu \mathrm{M}$. These data imply that DHP-sensitive channels (Ltype) are not required to trigger $\mathrm{K}^{+}$-evoked $\mathrm{ACh}$ release, suggesting DHP-insensitive, possibly $\mathrm{N}$-type $\mathrm{Ca}^{2+}$ channels as candidates for this role. Of course, $\mathrm{Ca}^{2+}$ channels in these cholinergic terminals may not conform to electrophysiological characteristics of channels in cell bodies of sympathetic or dorsal root ganglion cells.

\section{$\mathrm{Ca}^{2+}$ channels sensitive to DHPS}

The lack of inhibition of evoked ACh release by DHP antagonists does not prove that DHP-sensitive $\mathrm{Ca}^{2+}$ channels are absent from these nerve endings. Because the activation and inactivation of some types of $\mathrm{Ca}^{2+}$ channels are voltage dependent, the effect of prior depolarization on release was tested in choroid terminals. A $5 \mathrm{~min}$ predepolarization in $28 \mathrm{~mm} \mathrm{~K} \mathrm{~K}^{+}$ Tyrodes containing $10 \mu \mathrm{M}$ nifedipine also did not reveal any inhibition of subsequent $\mathrm{K}^{+}$-evoked $\mathrm{ACh}$ release (in 55 or 110 $\mathrm{mM} \mathrm{K}^{+}$) (see also Gray et al., 1989b). However, some DHP sensitivity could be uncovered when the evoked release period was preceded by a 60 sec predepolarization in $55 \mathrm{~mm} \mathrm{~K}^{+}$Tyrodes without $\mathrm{Ca}^{2+}$. Subsequent $\mathrm{K}^{+}$-evoked release in $3 \mathrm{mM} \mathrm{Ca}^{2+}$ was significantly reduced $(45 \% \pm 21$ of control evoked release, $p<$ $0.05, n=8$ ), as would be expected if a portion of the channels responsible for release were inactivated. Forty-two of the residual release after inactivation was, however, inhibited by nifedipine $(42 \% \pm 26$ inhibition of evoked ACh release after 28 $\mathrm{mm} \mathrm{K}^{+}, 0 \mathrm{Ca}^{2+}$ prepulse; $p<0.05, n=8$ ). One explanation for the slightly increased sensitivity of ACh release to nifedipine ( $22 \%$ of total evoked release) is that these cholinergic terminals contain 2 populations of voltage-dependent $\mathrm{Ca}^{2+}$ channels, DHP sensitive and DHP insensitive (Nowycky et al., 1985; Miller, 1987). The lack of effect of DHP antagonists on ACh release seen in Table 1 suggests that these DHP-sensitive, slowly inactivating channels normally play a less important role in $\mathrm{K}^{+}$evoked transmitter release than other $\mathrm{Ca}^{2+}$ channels. However, if DHP-insensitive channels are inactivated by $\mathrm{K}^{+}$predepolarization, $\mathrm{Ca}^{2+}$ entering by DHP-sensitive channels might then 
Figure 5. I, Effect of a DHP agonist, Bay K 8644, on release of ${ }^{3} \mathrm{H}$-ACh from choroid wedges. Clear bars in $I A$ represent controls; hatched bars in $I B$ represent tissues exposed to $0.5 \mu \mathrm{M}$ Bay K 8644 (hatched horizontal bar indicates time of application). In these experiments, a $25 \mathrm{~mm} \mathrm{~K} \mathrm{~K}^{+}$predepolarization step was included prior to evoked release to maximize Bay K 8644 binding to the DHP receptor. However, the Bay $\mathrm{K}$ 8644-induced inhibition of ${ }^{3}$ II-ACh release does not require this step (data not shown). Upper horizontal lines indicate the concentrations of $\mathrm{Ca}^{2+}$ and $\mathrm{K}^{+}$in the superfusate Tyrodes. ${ }^{*} p<$ 0.05 . II, Effect of Bay $\mathrm{K} 8644$ on ${ }^{3} \mathrm{H}$ ACh release in isolated irises. Hatchling irises were excised and treated as described for choroids, while clear and hatched bars represent similar condition to those in $I$. Note no effect of Bay $\mathrm{K} 8644$ on $\mathrm{ACh}$ release.
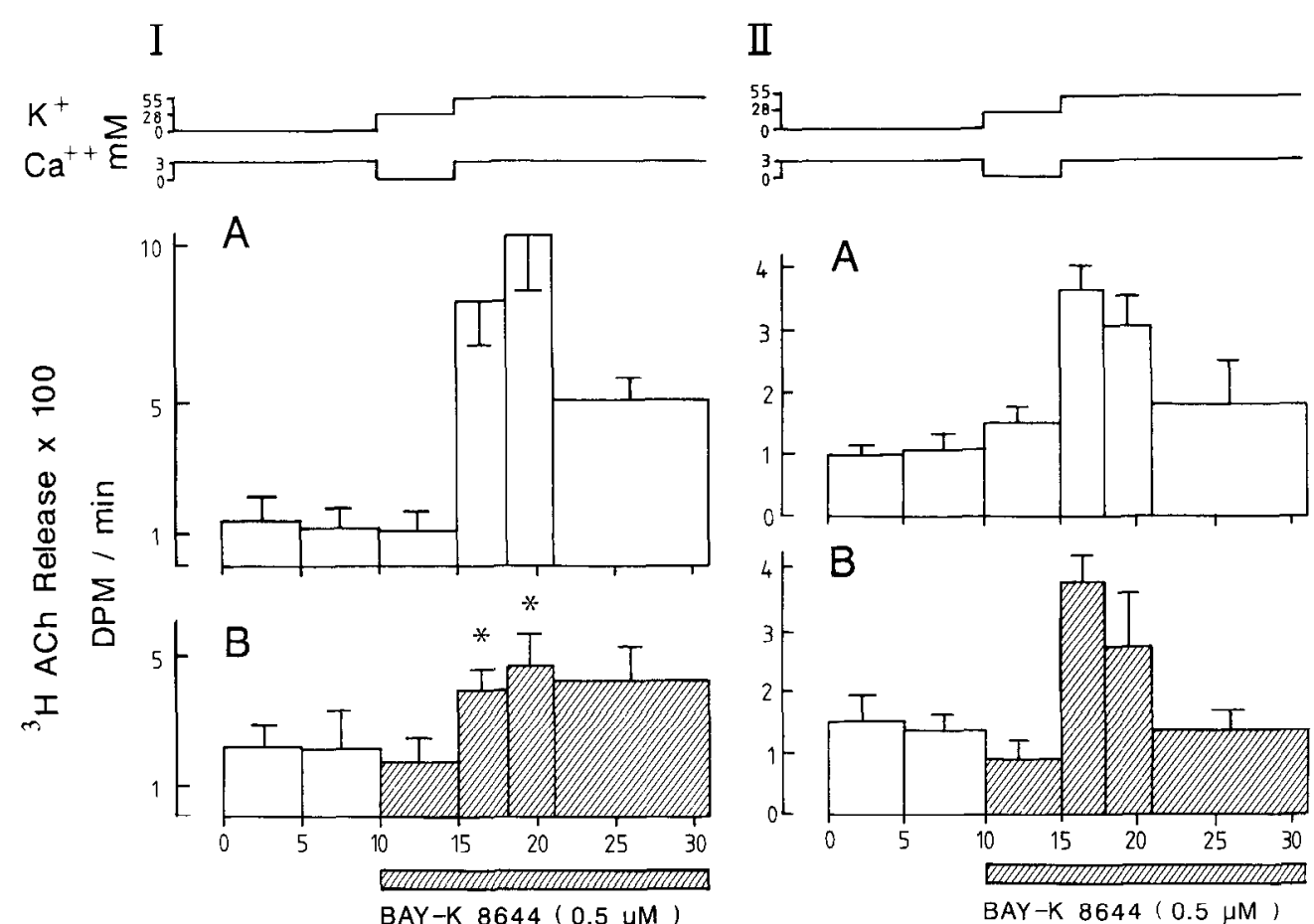

Time ( $\min$ )
BAY -K $8644(0.5 \mu \mathrm{M})$

Time $(\min )$ cause the release of $\mathrm{ACh}$ normally mobilized by $\mathrm{Ca}^{2+}$ entering via $\mathrm{DHP}$-insensitive channels.

The presence of multiple $\mathrm{Ca}^{2+}$ channels in these cholinergic terminals was pursued further by using Bay K 8644, a DHP agonist. We hypothesized that if L-type channels are present, this drug should enhance $\mathrm{Ca}^{2+}$ influx during depolarization and increase ACh release. Surprisingly, incubation with Bay K 8644 depressed evoked ${ }^{3} \mathrm{H}-\mathrm{ACh}$ release by more than $60 \%$ in the first two 3-min collection periods (Fig. $5 I B$, hatched) compared to controls (Fig. $5 I A$, clear). However, this apparently paradoxical

Table 1. Characterization of ${ }^{3} \mathrm{H}-\mathrm{ACh}$ release evoked by $\mathrm{K}^{+}$ depolarization

\begin{tabular}{lcc} 
Condition & Preincubation (min) & $\begin{array}{l}\% \mathrm{~K}^{+} \\
\text {stimulation }\end{array}$ \\
\hline Control & & 100 \\
$0 \mathrm{Ca}^{2+}$ & 40 & $-15 \pm 26^{a}$ \\
$\omega$-Conotoxin $(1 \mu \mathrm{M})$ & 10 & $-4 \pm 14^{a}$ \\
Cadmium $(100 \mu \mathrm{M})$ & 5 & $-7 \pm 12^{a}$ \\
Nifedipine $(10 \mu \mathrm{M})$ & 5 & $92 \pm 16$ \\
Verapamil $(10 \mu \mathrm{M})$ & 5 & $92 \pm 17$ \\
D600 $(10 \mu \mathrm{M})$ & 5 & $106 \pm 28$ \\
Somatostatin $100 \mathrm{nM}$ & 90 (SS for 5 min) & $4 \pm 12^{a}$ \\
Somatostatin and PTX & & $107 \pm 21$ \\
$\quad(200$ units/ml) & &
\end{tabular}

Values represent percentage of control ${ }^{3} \mathrm{H}-\mathrm{ACh}$ release evoked in $55 \mathrm{~mm} \mathrm{~K}$ Tyrodes for each condition. Incubation in high- $\mathrm{K}^{+}$Tyrodes evoked a mean $2.6-$ fold increase in ${ }^{3} \mathrm{H}$-ACh release uver basal prestimulation values. In $\mathrm{Ca}^{2+}$-free Tyrodes, the cation was omitted from the superfusate throughout the experiment. DHPs were dissolved in $0.1 \%$ DMSO. DMSO alone has no effect. SS, somatostatin. Values are mcans $\pm \mathrm{SE}$. Negative percentages indicate inhibition of basal release, as well as evoked release.

${ }^{a}$ Significantly different from controls; $p<0.05, n$ is at least 4 in all cases. effect would be expected if activation of L-type channels during Bay K 8644 application leads to release of endogenous somatostatin, a potent inhibitor of ACh release in the choroid coat (Gray ct al., 1989b). In support of this explanation, incubation with Bay K 8644 had no inhibitory effect on $\mathrm{ACh}$ release in preparations of the isolated iris (Fig. $5 I I A$ and $5 I I B$ ), which also has no endogenous somatostatin (Gray et al., 1989b).

\section{$\mathrm{Ca}+$ channels and somatostatin release}

To test whether inhibition of ACh release by Bay $\mathrm{K} 8644$ is mediated by endogenous somatostatin, we used a known somatostatin antagonist, $\mathrm{CyCam}$, which has been shown to reverse somatostatin inhibition of growth hormone release (Fries et al., 1982). Figure 6 shows that 5-10 $\mu \mathrm{M}$ CyCam maximally reverses the inhibition of $\mathrm{ACh}$ release caused by $100 \mathrm{~nm}$ exogenous somatostatin. We therefore used this concentration of CyCam in the succeeding experiments. This dose-response curve also shows that CyCam's inhibition of somatostatin's effect does not become apparent until the micromolar range and then decreases at CyCam concentrations over $10 \mu \mathrm{M}$. The rather narrow peak or range of maximum effect of CyCam may be caused by the direct inhibition of labeled $\mathrm{ACh}$ release by $\mathrm{CyCam}$ at concentrations greater than $10 \mu \mathbf{M}$ (unpublished observations).

This antagonism of exogenous somatostatin is useful since it provides a specific test for the involvement of endogenous somatostatin in phenomena affecting ACh release in the choroid. Figure 7 shows that preincubation with 2 agents known to reverse somatostatin's action in the choroid junctions can also prevent the Bay $\mathrm{K}$-induced inhibition of ACh release. For these experiments we used both CyCam and PTX, an antagonist of certain $\mathrm{G}$ proteins which previously had been shown to reverse inhibitory effects of exogenous somatostatin on choroid terminals (Table 1). In Figure $8, A-C$, Bay K 8644 alone in high- 


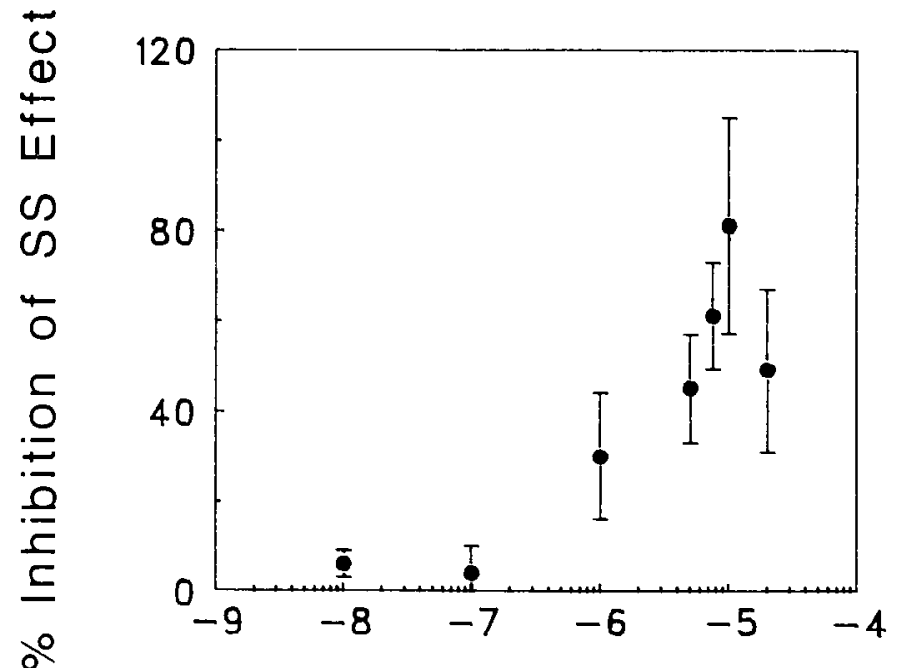

\section{CYCAM (M)}

Figure 6. Dose-response of somatostatin antagonist $(\mathrm{CyCam})$ on somatostatin-induced inhibition of ${ }^{3} \mathrm{H}-\mathrm{ACh}$ release. Values are expressed as a percentage of the reversal of $100 \mathrm{~nm}$ somatostatin inhibition of ${ }^{3} \mathrm{H}$ ACh relcasc. To calculate this value, each experiment contained control tissues and those exposed to $100 \mathrm{~nm}$ somatostatin. The percent inhibition of evoked release was calculated (evoked-prestimulation in somatostatin divided by evoked-prestimulation in controls) and subtracted from 100 to give a measure of inhibition of somatotstatin's effect. Values are means from 2 separate experiments, and bars are ranges.

$\mathrm{K}^{+}$Tyrodes significantly reduces $\mathrm{ACh}$ release relative to control stimulations. When either $10 \mu \mathrm{M}$ CyCam (Fig. 7A) or 200 units/ $\mathrm{ml}$ PTX (Fig. $7 B$ ) were preincubated with the preparation and present during the high- $\mathrm{K}^{+}$incubation, this reduction in $\mathrm{ACh}$ release was reversed.

Finally, coincubation of Bay K 8644 with $10 \mu \mathrm{M}$ nifedipine (Fig. $7 C$ ) also abolished the Bay $\mathrm{K} 8644$ inhibition of $\mathrm{K}^{+}$-evoked ${ }^{3} \mathrm{H}-\mathrm{ACh}$ release. This strongly supports the supposition that Bay $\mathrm{K} 8644$ is acting as a DHP agonist and that DHP-sensitive or $\mathrm{L}$-type $\mathrm{Ca}^{2+}$ channels are present in the nerve endings. CyCam, nifedipine, or PTX administered alone had no effect on $\mathrm{K}^{+}$evoked ${ }^{3} \mathrm{H}$-ACh release measured over the initial $3 \mathrm{~min}$ period (not shown).

Since incubation with CyCam or nifedipine alone did not significantly enhance normal $\mathrm{K}^{+}$-evoked release, we considered the possibility that somatostatin is not released in sufficient quantity to affect $\mathrm{ACh}$ release during high- $\mathrm{K}^{+}$incubation. One might expect high- $\mathrm{K}^{+}$incubation with Bay K 8644 to be more effective than $\mathrm{K}^{+}$incubation alone in releasing somatostatin because Bay K 8644 increases DHP-sensitive single-channel open time (Hess et al., 1984). However, it was also possible that we were not observing $\mathrm{ACh}$ release at the appropriate interval after the high- $\mathrm{K}^{+}$challenge to see the influence of an endogenously released inhibitory peptide. Thus, we screened the effects of the somatostatin antagonist (CyCam) and DHP antagonist (nifedipine) on prolonged release periods in case somatostatin release was slower or delayed relative to $\mathrm{ACh}$. Even in periods up to $30 \mathrm{~min}$ after exposure to high $\mathrm{K}^{+}$, no enhancement of labeled ACh release in the presence of CyCam was observed (data not shown). Conversely, ACh release in the initial minute after exposure to high $\mathrm{K}^{+}$was also examined. Figure 8 compares those initial values of labeled $\mathrm{ACh}$ release with values averaged
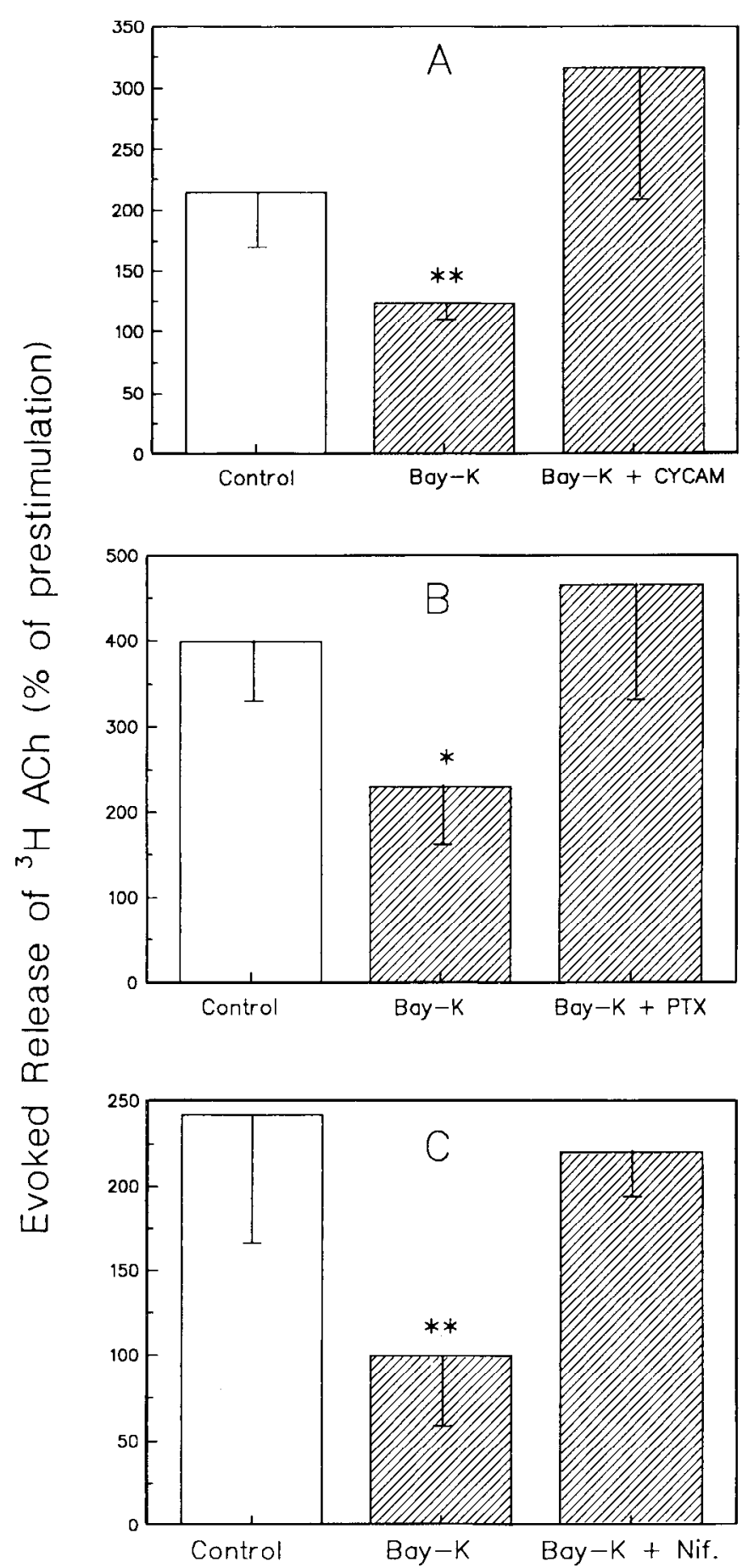

Figure 7. Reversal of Bay K 8644-induced inhibition of $\mathrm{K}^{+}$-evoked ${ }^{3} \mathrm{H}$-ACh release. Hatchling choroids were prepared and treated as described in Figure 5. The percent increase over prestimulation for the first $3 \mathrm{~min}$ period is presented for each control tube (clear bar) and compared to tubes in which Bay K 8644 and/or other agents are present (shaded bar). All agents were added $5 \mathrm{~min}$ prior to $\mathrm{K}^{+}$stimulation. $A$ represents effects of CyCam; $B, \mathrm{PTX} ; C$, nifedipine. $n=3$. ${ }^{*}$ Significantly different from controls at $p<0.05$. ${ }^{* *}$ Significantly different from controls at $p<0.02$.

over the first $4 \mathrm{~min}$ of release (the first minute plus the next 3 min) for both the choroid and iris preparations. Interestingly, there is a significant enhancement of $\mathrm{K}^{+}$-evoked ACh release in the presence of nifedipine (from 180 to $300 \%$ ) and CyCam (from 211 to $318 \%$ ) in the first minute of exposure to high $\mathrm{K}^{+}$in the 


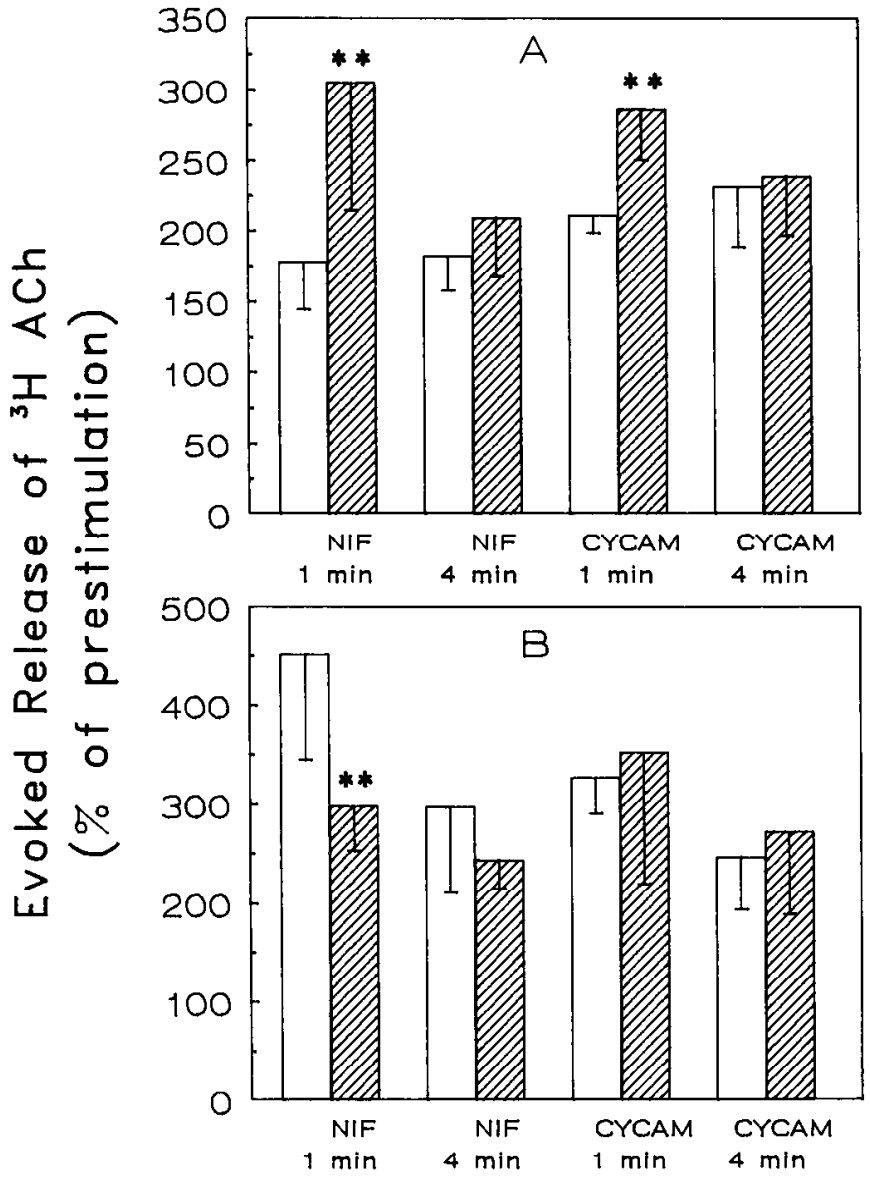

Figure 8. Effect of nifedipine and CyCam on the initial minute of $\mathrm{K}^{+}-$ evoked $A C h$ release in choroid $(A)$ and iris $(B)$. Hatchling choroids and irises were prepared and treated as described as in Figure 5, except that release samples were taken in the initial minute of exposure to $55 \mathrm{~mm}$ $\mathrm{K}^{+}$-containing Tyrodes and the following $3 \mathrm{~min}$ period as well. Values represent the percent increase in labeled $\mathrm{ACh}$ release over prestimulation values in the first minute of first 4 min (the first and the next 3 min) calculated on a per minute basis. The clear columns represent stimulated release in controls, while hatched bars represent experimental values. $n=4 ;{ }^{* *} p<0.02$.

choroid (Fig. 8A). This increase in ACh release appears to be due to inhibition of an endogenous somatostatin effect which is apparent within seconds after depolarization. However, these same values, when averaged with the next 3 min period, show no significant increase in labeled ACh release, agreeing with the original results for $3 \mathrm{~min}$ release periods in the choroid, expressed in Table 1. Thus, this inhibitory effect of coreleased somatostatin is terminated after $1 \mathrm{~min}$ by an unknown mechanism.

In the isolated iris (Fig. $8 B$ ) devoid of endogenous somatostatin there is no enhancement of ACh secretion even in the first minute of release, with either nifedipine or CyCam. Nifedipine does cause a significant inhibition of evoked $\mathrm{ACh}$ release in the 1 min period, suggesting that DHP-sensitive channels may be present also in those terminals.

Finally, Table 2 shows that the enhancement of $\mathrm{ACh}$ release in the initial minute by nifedipine in the choroid is not further increased by coincubation with $5 \mu \mathrm{M}$ CyCam. If DHP-insensitive calcium channels contribute significantly to somatostatin release, then selective blockade of only DHP-sensitive calcium
Table 2. Lack of additive effect of nifedipine and CyCam on the initial minute of ${ }^{3} \mathrm{H}$-ACh release evoked by $\mathrm{K}^{+}$depolarization in the choroid

\begin{tabular}{ll} 
Condition & $\begin{array}{l}\text { Evoked release } \\
\text { of ACh in first } \\
\text { minute } \\
\text { (\% over basal) }\end{array}$ \\
\hline Control & $250 \pm 49$ \\
+ Nifedipine & $352 \pm 56^{a}$ \\
+ Nifedipine and CyCam $(5 \mu \mathrm{M})$ & $345 \pm 41^{a}$
\end{tabular}

Experimental conditions are the same as described in Figure 8. Values represen percent increase in ${ }^{3} \mathrm{H}-\mathrm{ACh}$ release evoked in $1 \mathrm{~min}$ of $55 \mathrm{~mm} \mathrm{~K}{ }^{+}$Tyrodes for each condition. Values are means $\pm \mathrm{SE}$.

"Significantly different from controls; $p<0.05, n=4$.

channels would be expected to enhance $\mathrm{ACh}$ release to a much smaller extent than blockade of the somatostatin receptor (by CyCam), which is at a final common pathway. Since this is not the case, the evidence supports the suggestion that little somatostatin release is mediated by calcium influx through DHP. insensitive channels.

\section{Discussion}

In a previous study, we provided evidence at the light microscopic level in the choroid junction that $\mathrm{ACh}$ and somatostatin may be colocalized (Gray et al., 1989b). In this report, we show further support for colocalization of synaptic vesicles and somatostatin-like immunoreactivity, as well as a correlation between choroid cells in the ganglion and somatostatin. ${ }^{1}$ We also provide circumstantial but compelling evidence that both substances can be released by $\mathrm{K}^{+}$depolarization that involves $\mathrm{Ca}^{2+}$ entry via pharmacologically different $\mathrm{Ca}^{2+}$ channels, ACh preferentially through the DHP-resistant and perhaps rapidly inactivating channels and somatostatin via the DHP-sensitive, slowly inactivating (L-type) channels. Furthermore, we also provide evidence that transmitter release evoked by a $1 \mathrm{~min}$ incubation in high $\mathrm{K}^{+}$is enhanced by a somatostatin inhibitor. This implies that endogenous somatostatin is secreted under physiological conditions and can inhibit the initial portion of ACh release.

Somatostatin is a versatile hormone, present in the gastrointestinal tracts and pancreas, where it inhibits the release of some gut hormones, and in the hypothalamus, where it controls the secretion of growth hormone and thyrotrophin-secreting hormone. It is also present in the nervous system, in the hippocampus, the cortex, and the PNS (Meyers and Coy, 1980). Somatostatin regulates the activity of smooth muscle by modulating the neuronal release of cholinergic (Guillemin, 1976) and adrenergic (Cohen et al., 1978) transmitters. The studies reported here shed some light on how somatostatin executes its action and what mechanisms are involved in the presynaptic regulation of transmitter output. In the hippocampus and cerebral cortex, somatostatin depresses the neuronal activity in vivo, although

\footnotetext{
' In Figure 2 we show that some large somatostatin-positive neurons are scattered through the ciliary neuron region of the ganglion, although most are near the demarcation zone between ciliary and choroid regions. The identity and targets of these cells are not clear. They may be neurons that innervate nonchoroid structures, choroid cells that are not segregated with the majority, or ciliary neurons that transiently express somatostatin. In any case, these cells represent only a small fraction of ganglion neurons and do not significantly affect the dichotomy of somatostatin expression between ciliary and choroid neurons.
} 


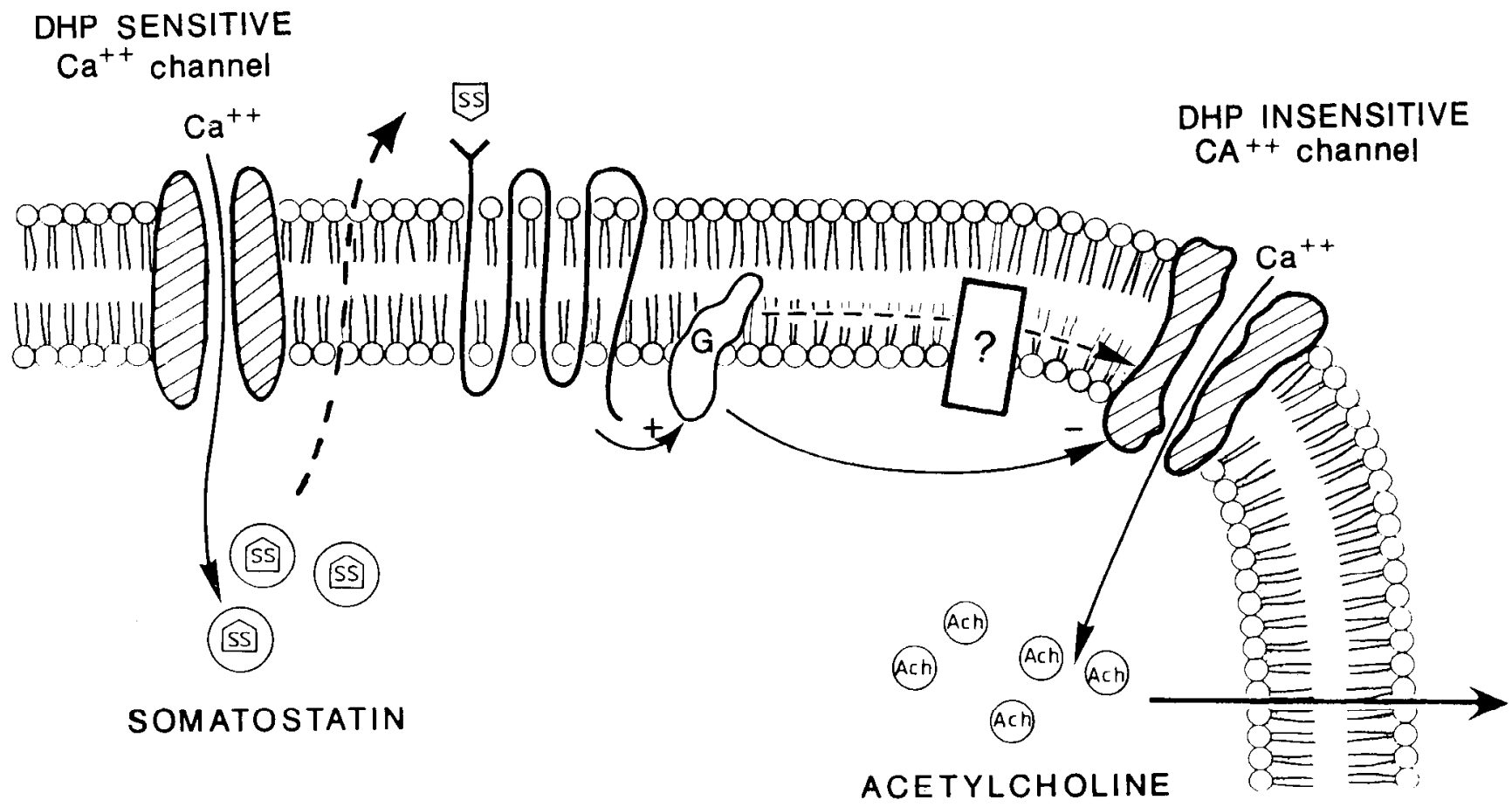

Figure 9. Schematic representation of a mechanism for neuromodulation of transmitter release at the choroid neuron terminal. In this model, $\mathrm{ACh}$ and somatostatin are contained in separate vesicles within a varicosity of a choroid neuron axon innervating vascular smooth muscle. Ca ${ }^{2+}$ entry into the terminal through a dihydropyridine-sensitive voltage-dependent $\mathrm{Ca}^{2+}$ channel triggers exocytotic release of the endogenous peptide, somatostatin. Somatostatin then binds to a receptor site on the membrane, which activates a pertussis toxin-sensitive GTP-binding protein (labeled $G)$. The activated $\mathrm{G}$ protein causes a decrease in conductance of a voltage-activated, dihydropyridine-insensitive $\mathrm{Ca}^{2+}$ channel, either directly, within the membrane, or, indirectly, by an unknown second messenger (box). The decrease in $\mathrm{Ca}^{2+}$ entry through the latter $\mathrm{Ca}^{2+}$ channel leads to an inhibition of exocytotic ACh release. Arrow with plus sign indicates activation, arrow with minus sign indicates inhibition.

exogenously applied somatostatin increases the neuronal firing elicited by applied ACh (Mancillas et al., 1986). Some of these effects could also be due to a postsynaptic action of somatostatin. It is also of interest that somatostatin-containing neurons may interact with intrinsic cholinergic systems in the cortex (Delfs et al., 1984). Also, Alzheimer's patients show a diminution of cholinergic innervation and somatostatin levels (Davies, 1979; Davies et al., 1980). We are far from explaining the many functions of somatostatin. Rather, the importance of these results is in understanding the mechanisms by which somatostatin is secreted in the nervous system.

\section{Colocalization of somatostatin and $A C h$}

The demonstration that somatostatin-like immunoreactivity is concentrated in the choroid region of the ganglion provides clear evidence for colocalization of this peptide in cholinergic neurons. This is further supported by the similar patterns of staining for somatostatin and neurofilament staining in the choroid (Gray et al., 1989b) and SV2 staining (a well-characterized antibody to synaptic vesicle antigen) (Buckley and Kelly, 1985) in this report. The EM photograph also shows dense-core vesicles in the same terminal or release site as smaller, clear vesicles. This small ratio of dense-core vesicles to clear vesicles could explain the relatively faint somatostatin stain observed when compared with the cytoskeleton or SV2 antibodies, although there is no direct evidence yet that somatostatin is contained in the densecore vesicles.

\section{$C a^{2+}$ channels and the release of $A C h$ and somatostatin}

If $\mathrm{ACh}$ and neuropeptides are separately released by $\mathrm{Ca}^{2+}$ entry through distinct channels, then these cholinergic terminals must contain at least 2 populations of voltage-dependent $\mathrm{Ca}^{2}$ channels, DHP sensitive and DHP insensitive. This has recently been shown in an isolated presynaptic preparation (Lemos and Nowycky, 1989) and in other preparations in which transmitter release is measured indirectly (Perney et al., 1986; Atchison and O'Leary, 1987). This is also true in the choroid coat, since a DHP agonist effect is reversed by a DHP antagonist, providing strong support for the existence of DHP-sensitive $\mathrm{Ca}^{2+}$ channels in these terminals. Likewise, the simultaneous presence of $\mathrm{Ca}^{2+}$ dependent, $\omega$-conotoxin-sensitive but DHP antagonist-insensitive transmitter release supports the coexistence of DHP-insensitive $\mathrm{Ca}^{2+}$ channels (at least under these conditions). Given the current uncertainty of the link between DHP sensitivity and L channels (see Plummer et al., 1989) in neurons, it is unclear if the 2 populations of channels (DHP sensitive and insensitive) represent $2 \mathrm{~L}$-types, an $\mathrm{N}$ - and L-type, $2 \mathrm{~N}$-types, or an entirely new kind of voltage-dependent $\mathrm{Ca}^{21}$ channel. Figure 9 is a schematic representation of the mechanism of neuromodulation at a choroid terminal which incorporates the findings from this report and from our earlier study (Gray et al., 1989b). In this model, ACh and somatostatin are colocalized in the same nerve process, which also contains both DHP-sensitive and -insensitive types of voltage-dependent $\mathrm{Ca}^{2+}$ channels. Activation of 
DHP-sensitive channels allows inward $\mathrm{Ca}^{2+}$ flux that triggers somatostatin release from the terminal. This somatostatin binds to presynaptic receptors on its process, activating a $\mathrm{G}$ protein. The activation of this $G$ protein (which is PTX sensitive) decreases $\mathrm{Ca}^{2+}$ flux through voltage-activated DHP-insensitive $\mathrm{Ca}^{2+}$ channels. This interaction between channel and regulatory protein may either be direct within the membrane or may involve a still unknown cellular second messenger (Gray et al., 1989b). Decreased $\mathrm{Ca}^{2+}$ entry through this channel leads to a decrease in ACh relcase from terminals. Following this scheme it is clear why Bay K 8644 activation of DHP-sensitive $\mathrm{Ca}^{2+}$ channels may lead to somatostatin release and thus local inhibition of evoked ACh release. Conversely, antagonism of these channels by nifedipine decreases somatostatin release and thus enhances ACh release. The fact that further block of this pathway with the somatostatin antagonist CyCam (added together with the nifedipine) does not result in any further enhancement of $\mathrm{ACh}$ release also supports the suggestion that only DHPsensitive channels contribute to somatostatin release.

The reason that $\mathrm{Ca}^{2+}$ influx into terminals through DHP-sensitive channels does not trigger $\mathrm{ACh}$ release is unclear, but it may be that there are fewer DHP-sensitive channels than DHPinsensitive channels in the terminals or that there is selective localization of N-type channels close to the releasable $\mathrm{ACh}$ pool (Augustine et al., 1987). These 2 alternatives are not necessarily mutually exclusive. Our results and those of Atchison and O'Leary (1987) on transmission at the rat neuromuscular junction suggest the colocalization of DHP-insensitive and -sensitive channels in the terminals of each preparation but reinforce our conclusion that it is primarily the DHP-insensitive channels that are involved in $\mathrm{ACh}$ release. This division of function has also been demonstrated in sympathetic neuron cell bodies where norepinephrine modulates somal transmitter release via $\mathrm{N}$-like channels identified electrophysiologically (Lipscombe et al., 1989). The increase in evoked ACh release in Figure $7 A$ in the presence of both Bay K 8644 and CyCam suggests that when somatostatin's effects are subtracted, increased calcium influx through an $\mathrm{L}$ channel may enhance $\mathrm{ACh}$ release. However, it must be noted that this apparent increase is not statistically significant for these samples.

\section{DHPs and $\mathrm{Ca}^{2+}$ channel characterization}

Using DHP sensitivity as an assay for L-type $\mathrm{Ca}^{2+}$ channel activity has recently come under criticism due to DHP binding kinetics and effects of $G$ protein activation. However, arguments for nonspecific or incomplete action of DHPs (on L channels) in the choroid appear to be unlikely for the following reasons.

An alternative explanation for the DHP agonist-induced inhibition of $\mathrm{ACh}$ release involves the possible "switching" of Bay K 8644 to an antagonist. Previously, it was shown that activation of $G$ proteins could change the action of a DHP antagonist to that of a DHP agonist (Scott and Dolphin, 1987). We considered that this conversion could be responsible for the reduction in ACh release induced by Bay K 8644 (acting now as an antagonist) instead of acting via release of somatostatin. However, this possibility is remote since we show that the potential contribution of $\mathrm{Ca}^{2+}$ entry through L-type channels for ACh release is relatively small. Nevertheless, if this were the case, addition to the superfusate of a traditional DHP antagonist should enhance the Bay K 8644 inhibitory effect. Quite to the contrary, $10 \mu \mathrm{M}$ nifedipine blocked the Bay K 8644 effect, indicating that Bay K 8644 was acting as an agonist (Fig. $8 C$ ).
Another concern involving the use of DHPs is their controversial efficacy in blocking L-type $\mathrm{Ca}^{2+}$ channels in many preparations (Hess et al., 1984; review by Miller, 1987; Bean, 1989a; Plummer et al., 1989). Thus, the lack of antagonism of ACh release by nifedipine may be construed as inadequate binding of the drug to an L-like channel in the terminal, due to voltage dependence. This voltage-dependent binding affinity (Lee and Isien, 1983; Sanguinetti and Kass, 1984) has been used to explain the apparent lack of effect of DHP antagonists on transmitter relcasc in cultured ganglion cells (Holz et al., 1988). However, for several reasons we do not favor this explanation. First, Holz et al. demonstrated that in cultured dorsal root ganglion neurons, high- $\mathrm{K}^{+}$-evoked transmitter release, in contrast to that evoked by electrical stimulation, is DHP sensitive, due to the sustained nature of the depolarization. Second, we have shown previously that preincubation in $25 \mathrm{~mm} \mathrm{~K}, 0-\mathrm{Ca}^{2+}$ Tyrodes, which might be expected to depolarize cells sufficiently to cause enhanced binding of DHP (Sanguinetti and Kass, 1984), has no effect on subsequent release of ACh (even with $50 \mu \mathrm{M}$ nifedipine) (Hess et al., 1984; Gray et al., 1989b). Finally, when DHPsensitive channels are revealed by Bay K 8644 in the first minute of $\mathrm{ACh}$ release, nifedipine indirectly affects $\mathrm{ACh}$ release without a predepolarization step. In the inactivation experiment, a $0-\mathrm{Ca}^{2+}$ prepulse also "uncovers" a small amount of DHP-sensitive ACh release. Although we cannot speculate about $\mathrm{Ca}^{2+}$ channel kinetics from this study, we do interpret these results to demonstrate DHP-sensitive channels in this preparation.

\section{Time course of endogenous somatostatin effect}

The lack of any enhancing effect of nifedipine or other DHP antagonists on $\mathrm{ACh}$ release (Table 1) was puzzling at first in light of our hypothesis that endogenous somatostatin was released by $\mathrm{Ca}^{2+}$ entry via DHP-sensitive channels. At first we concluded that somatostatin might not be released by high- $\mathrm{K}^{+}$ incubation without the addition of Bay $\mathrm{K} 8644$. As demonstrated in Figure $7 A$, however, it is only in the initial minute of the release period that an endogenous somatostatin effect can be observed indirectly. If this initial minute is averaged with the next $3 \mathrm{~min}$, the enhancement of $\mathrm{ACh}$ release is occluded (Fig. $7 A$ ). These results, also seen with the somatostatin antagonist in the choroid, imply that the role of endogenous somatostatin is transitory ( $<1 \mathrm{~min}$ ) under this stimulation paradigm (Fig. $7 A$ ). There are several possible explanations for this transience. First, the somatostatin may be released only during this time period, or second, somatostatin may be inactivated soon after release, or third, the effect of somatostatin itself may be transitory. This last possibility has been shown by Bean (1989b) in cultured bullfrog dorsal root ganglion cells bodies, where depression of $\mathrm{Ca}^{21}$ current by somatostatin relaxed back to control levels within 20-50 msec. However, in the choroid coat, exogenous somatostatin inhibits ACh release for over $6 \mathrm{~min}$ (Gray et al., 1989b). Another hypothesis is that somatostatin may inhibit $\mathrm{Ca}^{2+}$ entry through DHP-sensitive channels necessary for its own release as well as channels responsible for $\mathrm{ACh}$ release. Thus, somatostatin may be released in "waves" of 30 sec or so, delimited in time by its own autoregulatory feedback, freeing ACh release from inhibition until the next nerve stimulus that is able to cause peptide release. However, there is no evidence now to decide among these hypotheses. Finally, the complete lack of enhancement of ACh release with either nifedipine or the somatostatin antagonist in the iris preparation (which lacks somatostatin) strongly supports the role of somatostatin 
as an endogenous neuromodulatory peptide in choroid terminals (Figs. 2, $A, B, 5 I I, 6 B$ ).

In this report we have essentially used inhibition of ${ }^{3} \mathrm{H}-\mathrm{ACh}$ release from the choroid as a bioassay for somatostatin release. Currently we are measuring somatostatin release directly, using radioimmune assay and also determining if electrical stimulation of the choroid nerve terminals will also cause somatostatin release. 'These measurements will test our hypotheses directly and may answer the questions dealing with physiological relevance of ncuromodulation in the choroid system. However, the present study provides the first pharmacological evidence for specific roles of different voltage-dependent $\mathrm{Ca}^{2+}$ channels in controlling the release of a neurotransmitter and its modulator from the same population of terminals. Furthermore, these results suggest distinct secretory pathways in choroid terminals, one for the classical transmitter ACh and the other for its modulator, somatostatin, allowing their selective activation and regulation by action potential frequency modalities and second messengers or hormones. It will be important to demonstrate the generality of these findings to more physiological stimulation paradigms and to synapses in the CNS.

\section{References}

Allen JM, Adrian TE, Tatemoto K, Polak JM, Hughes J (1982) Two novel related peptides, neuropeptide Y (NPY) and peptide YY (PYY) inhibit the contraction of the electrically stimulated mouse vas deferens. Neuropeptides 3:71-77.

Atchison WD, O'Leary SM (1987) BAY K 8644 increases release of acetylcholine at the murine neuromuscular junction. Brain Res 419 . 315-319.

Augustine G, Charlton MP, Smith SJ (1987) Calcium action in synaptic transmitter release. Annu Rev Neurosci 10:175-198.

Bartfai T, Iverfeldt K, Fisone G (1988) Regulation of the release of coexisting neurotransmitters. Annu Rev Pharmacol Toxicol 28:285309.

Bean B (1989a) Classes of calcium channels in vertebrate cells. Annu Rev Physiol 51:367-384.

Bean B (1989b) Neurotransmitter inhibition of neuronal calcium currents by changes in channel voltage dependence. Nature 340:153156.

Buckley K, Kelly R (1985) Identification of a transmembrane glycoprotein specific for secretory vesicles of neuronal and endocrine cells. J Cell Biol 100:1284-1294.

Campbell G, Jackson F (1985) Independent co-release of acetylcholine and somatostatin from cardiac vagal neurones in toad. Neurosci Lett $60: 47-50$.

Carbone E, Lux HD (1983) A low voltage-activated fully inactivating $\mathrm{Ca}$ channel in vertebrate sensory neurones. Nature 310:501-502.

Cohen ML, Rosing E, Wiley KS, Slater IH (1978) Somatostatin inhibits adrenergic and cholinergic neurotransmission in smooth muscle. Life Sci 23:1659-1664.

Davies P (1979) Neurotransmitter-related enzymes in senile dementia of the Alzheimer type. Brain Res 171:319-327.

Davies P, Katzman R, Terry RD (1980) Reduced somatostatin-like immunoreactivity in cerebral cortex from cases of Alzheimer disease and Alzheimer senile dementia. Nature 288:279-280.

Delfs JR, Zhu C-H, Dichter MA (1984) Coexistence of acetylcholinesterase and somatostatin immunoreactivity in neurons cultured from rat cerebrum. Science 223:61-63.

Epstein ML, Davis JP, Gellman LE, Lamb JR, Dahl JL (1988) Cholinergic neurons of the chicken ciliary ganglion contain somatostatin. Neuroscience 25:1053-1060.

Fries JL, Murphy WA, Sueiras-Diaz J, Coy DH (1982) Somatostatin antagonist analog increases $\mathrm{GH}$, insulin, and glucagon release in the rat. Peptides 3:811-814.

Gray DB, Pilar G (1988) Differential role of $\mathrm{Ca}^{++}$channels in the release of ${ }^{3} \mathrm{H}-\mathrm{ACh}$ and its modulation. Soc Neurosci Abstr 14:646.

Gray DB, Manthay N, Zelazny D (1989a) Nifedipine, a L-type $\mathrm{Ca}^{++}$ channel blocker, enhances $\mathrm{ACh}$ release from populations of terminals also expressing somatostatin-like immunoreactivily. Soc Neurosci Abstr 15:473.

Gray DB, Pilar GR, Ford MJ (1989b) Opiate and peptide inhibition of transmitter release in parasympathetic nerve terminals. J Neurosci 9:1683-1692.

Guillemin R (1976) Somatostatin inhibits the release of acetylcholine induced electrically in the myenteric plexus. Endocrinology 99:16531654.

Hess P, Lansman JB, Tsien RW (1984) Different modes of Ca channel gating behaviour favoured by dihydropyridine $\mathrm{Ca}$ agonists and antagonists. Nature 311:538-544.

Hirning LD, Fox AP, McClcskcy EW, Olivera BR, Thayer S $\Lambda$, Miller RJ, Tsien RW (1988) Dominant role of $\mathrm{N}$-type $\mathrm{Ca}^{++}$channels in evoked release of norepinephrine from sympathetic neurons. Science 239:57-61.

Hökfelt T, Fuxe K, Pernow B (1987) Coexistence of neuronal messengers: a new principle in chemical transmission. Prog Brain Res 68: $1-411$.

Holz GG, Dunlap K, Kream R (1988) Characterization of the electrically evoked release of substance $\mathrm{P}$ from dorsal root ganglion neurons: methods and dihydropyridine sensitivity. J Neurosci 8:463471.

Jan LY, Jan YN (1982) Peptidergic transmission in sympathetic ganglia of the frog. J Physiol (Lond) 327:219-246.

Lee KS, Tsien RW (1983) Mechanisms of calcium channel blockade by verapamil, D600, diltiazcm and nitrendipine in single, dialyzed heart cells. Nature 302:790-794.

Lemos JR, Nowycky M (1989) Two types of calcium channels coexist in peptide-releasing vertebrate nerve terminals. Neuron 2:1419-1426.

Lipscombe D, Kongsamut S, Tsien RW (1989) $\alpha$-Adrenergic inhibition of sympathetic neurotransmitter release mediated by modulation of N-type calcium-channel gating. Nature 340:639-642.

Lundberg JM, Anggard A, Fahrenkrug J (1981) Complementary role of vasoactive intestinal polypeptide (VIP) and acetylcholine for cat submandibular gland blood flow and secretion. II. Effects of cholinergic antagonists and VIP antiserum. Acta Physiol Scand 113:329336.

Mancilla JR, Siggins GR, Bloom FE (1986) Somatostatin selectively enhances acetylcholine-induced excitations in rat hippocampus and cortex. Proc Natl Acad Sci USA 83:7518-7521.

McClesky EW, Fox AP, Feldman DH, Cruz LJ, Olivera BM, Tsien RW, Yoshikami D (1987) $\omega$-Conotoxin: direct and persistent blockade of specific types of calcium channels in neurons but not muscle. Proc Natl Acad Sci USA 84:4327-4331.

Meriney SD, Pilar G (1987) Cholinergic innervation of the smooth muscle cells in choroid coat of the chick eye and its development. $J$ Neurosci 7:3827-3839.

Meyers CA, Coy DH (1980) Somatostatin, enkephalins, and endorphins. In: Gastrointestinal hormones (Glass GBJ, ed). New York: Raven Press.

Miller RJ (1987) Multiple calcium channels and neuronal function Science 235:46-52.

Miller RJ (1988) Calcium signalling in neurons. Trends Neurosci 11: 415-419.

Nowycky MC, Fox AP, Tsien RW (1985) Three types of neuronal calcium channel with different calcium channel sensitivity. Nature 316:440-443.

Pang DC, Sperelakis N (1983a) Nifedipine, diltiazem, bepridil, and verapamil uptakes into cardiac and smooth muscles. Eur J Pharmacol 87:199-207.

Pang DC, Sperelakis N (1983b) Uptake of (3H) nitrendipine into cardiac and smooth muscles. Biochem Pharmacol 32:1660-1663.

Perney TM, Hirning LD, Leeman SE, Miller RJ (1986) Multiple calcium channels mediate neurotransmitter release from peripheral neurons. Proc Natl Acad Sci USA 83:6656-6659.

Pilar G, Landmesser L, Burstein L (1980) Competition for survival among developing ciliary ganglion cells. J Neurophysiol 43:233-253.

Plummer MR, Logothetis DE, Hess P (1989) Elementary properties and pharmacological sensitivities of calcium channels in mammalian peripheral neurons. Neuron 2:1453-1461.

Sanguinetti MC, Kass RS (1984) Voltage dependent block of calcium channel current in the calf cardiac purkinje fiber by dihydropyridine calcium channel antagonists. Circ Res 55:336-348.

Scott RH, Dolphin AC (1987) Activation of a $G$ protein promotes agonist responses to calcium channel ligands. Nature 330:760-762. 
Vaca K, Pilar G (1979) Mechanisms controlling choline transport and acetylcholine synthesis in motor nerve terminals during electrical stimulation. J Gen Physiol 73:605-628.

Yeager RE, Yoshikami D, Rivier J, Cruz LJ, Miljanich GP (1987)
Transmitter release from presynaptic terminals of electric organ: inhibition by the calcium channel antagonist, omega Conus toxin. J Neureosci 7:2390-2396. 